\title{
College Students' Attitudes and Behaviors Related to Sun Safety and Appearance in Relation to Health Information-Seeking Behavior and Social Media Use: Cross-Sectional Study
}

Corey H Basch ${ }^{1}$, EdD, MPH; Grace C Hillyer ${ }^{2}$, EdD, MPH; Rachelle-Ann Romero ${ }^{1}$; Sarah A MacLean ${ }^{3}$, BA; Danna Ethan ${ }^{4}, \mathrm{MSW}, \mathrm{EdD}$

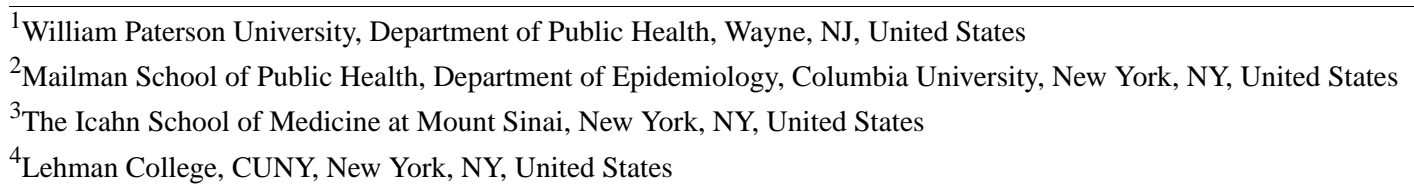

\section{Corresponding Author:}

Corey H Basch, EdD, MPH

William Paterson University

Department of Public Health

366 University Hall

Wayne, NJ, 07470

United States

Phone: 19737202603

Fax: 19737202215

Email: baschc@wpunj.edu

\section{Abstract}

Background: Skin cancer is the most common type of cancer in the United States. Rates of melanoma, a malignant form of skin cancer, are on the rise and are high among people under 30 years of age.

Objective: This study aims to explore factors related to sun protection and tanning behavior and examine the influence of social media use and health information-seeking behaviors (HISB) on sun protection actions among a group of college students.

Methods: In this cross-sectional study, students $(\mathrm{N}=258)$ at a large public university completed a survey that included questions on sun safety and tanning attitudes and behaviors, as well as HISB. A sun protection behavior score was created on the basis of behaviors related to seeking shade, using sunscreen, tanning booth and bed use, and the number of lifetime blistering sunburns. Multivariate logistic regression analyses were performed to assess associations between high and low sun protection behavior and sun safety and tanning attitudes and HISB.

Results: The majority of participants were females (164/258, 63.8\%), 31.0\% (80/258) were white, and the mean age was 20.3 (SD 4.1) years. Females (odds ratio [OR] 0.42, 95\% CI 0.22-0.81) and believers that suntan improves appearance (OR $0.25,95 \%$ CI 0.10-0.66) were less likely to have "high" sun protection behaviors.

Conclusions: The cultural belief that having a suntan improves appearance, especially among female college students, results in low sun protection behaviors. Interventions can be developed to improve skin cancer-related HISB among college students with the aim of developing better cognizance of skin cancer and sun protection behaviors.

(JMIR Dermatol 2018;1(2):e10984) doi: 10.2196/10984

\section{KEYWORDS}

United States; universities; students; skin neoplasms; ultraviolet rays

\section{Introduction}

Skin cancer is the most common type of cancer in the United

States [1]. Rates of melanoma, a malignant form of skin cancer, have risen over the years [1,2]. The American Cancer Society estimates there will be 99,550 new cases of skin cancer in 2018 , excluding basal and squamous types (as there is no requirement to report these to cancer registries), of which, 91,270 (92\%) are melanoma [3]. In addition, a recent study suggested that the number of individuals diagnosed with melanoma will nearly 
double in 2026-2031 [4]. Melanoma is among the most common cancers in people under 30 years of age [4]. Ultraviolet exposure is a well-known risk factor for the development of melanoma [5]. College students tend to have high levels of sun exposure, low levels of concern for sun protection, and a strong desire to suntan [6-10].

Behaviors can be influenced by a number of factors, one of which is social media. The use of digital platforms, particularly social media, is at an all-time high [11]. The emergence of social media has allowed individuals opportunities in networking, navigation, and real-time connection [11,12]. College-aged individuals, who are part of a technologically adapted generation, frequently use social media, with $88 \%$ of those aged 18-29 years reporting that they are using social media [13]. College-aged individuals (age: 18-24 years) are markedly more likely to use Twitter, Snapchat, and Instagram, highly popular social media platforms [13]; of individuals in this age bracket, $51 \%$ reported that social media would be difficult for them to give up [13]. These young consumers are regularly productive through social media (eg, messaging, searching, sharing, and discussing various topics) [12]. As individuals continue to embrace social media, public health professionals should be aware of the potential health implications in nature of the information and messages that are accessed or shared.

One study specifically examined social media use and indoor tanning behavior and determined that social media is a medium that could increase peer pressure to partake in indoor tanning [14]. College-aged individuals, particularly women, are among individuals that frequently $\tan [15,16]$ and use social media [13]. As social media is so widespread, there are potential risks in spreading messages that could endanger health. As active information and image sharing on these platforms may be encouraging indoor tanning [14], a concern should be raised as indoor tanning is a major risk factor for skin cancer [17].

With the use of social media on the rise, there is a heightened sensitivity to self-image and physical appearance among younger age groups [18-20]. Many of these individuals associate tanned skin to attractiveness. Recent studies indicated that appearance dissatisfaction and tanning intentions strongly associated with social media use $[18,21]$. Current literature regarding social media $[18,22]$ is consistent with research on traditional media in that images are often pro-tan and lack focus on skin cancer prevention [23-27].

As social media is reportedly used to promote tanning activity [28], it can also be used to promote health and can be highly effective as a medium for disseminating information in this population and promoting prevention efforts [29,30]. There remains a gap in the literature in terms of health information-seeking behaviors (HISB) of college students when it comes to skin cancer. Therefore, this study aims to explore factors related to sun protection and tanning behavior and examine the influence of health information seeking on sun protection behaviors among a group of college students.

\section{Methods}

This cross-sectional study, conducted in March-May of 2018, was ancillary to a larger study that focused on HISB of college students in general [31]. Instructors of 9 sections of a personal health course at a large public university in New Jersey distributed surveys to all students who were present $(n=329)$ in class and voluntarily participated $(n=258)$. The response rate was $78.4 \%$. Of note, the course is part of the University Core Curriculum in which all students must take a personal health course, and this course is one of the offerings. Survey questions were adapted from the Health Information National Trends Survey questionnaire, and from our prior study on sun safety [6]. The survey questions pertinent to this study are described below.

Sun safety and tanning behaviors were captured in 5 questions. Sun safety behaviors were measured in 2 questions aimed at the likelihood that respondents would (1) seek shade; and (2) use sunblock on a sunny day. In addition, tanning behaviors were captured in 2 questions that encompassed the likelihood that respondents would go indoor tanning and specifically how many times they have used a tanning booth and bed in the past 12 months. The overall exposure was measured by asking how many blistering sunburns respondents experienced in their lives.

When looking at reasons for tanning and sun protection, we queried students regarding their perceived satisfaction in appearance and whether they believed that having a tan improves appearance. Moreover, we included questions concerning self-esteem and stress to further investigate the influence of social factors and individual thoughts and beliefs about the tanned skin. Appearance-based questions included the following: Have you ever been dissatisfied with your appearance? Are you currently satisfied with your physical appearance? Do you think having a suntan improves your appearance? Do you think having a suntan improves your self-esteem?Do you think sun-tanning or sunbathing is a way to relieve stress?

Respondents were asked questions related to HISB, specifically how many hours per day they were engaged on social media. Furthermore, questions were posed to assess respondents' attitudes toward the accuracy of information on social media, in general, and beliefs related to the helpfulness of social media as resources for health issues.

Descriptive analyses included frequency distributions, mean, median, and range. To construct the outcome variable, "sun protection behaviors," the following variables were recoded and summed: seek shade on sunny days ("likely" or "very likely"), use sunscreen on sunny days ("likely" or "very likely"), use a tanning booth and bed ("very unlikely" or "unlikely"), zero times using a tanning booth and bed in the past 12 months, and zero blistering sunburns in one's lifetime. The potential range of the 5 variables was $0-5$; mean and median scores were 3.1 (SD 1.0) and 3.0, respectively. The sun protection behavior score was dichotomized with values of $0-3$ coded as "low" sun protection behaviors and values of 4-5 as "high" sun protection behaviors. The race was recoded as black or African American individuals versus all other races and college year as "freshmen" versus "upper classmen." Variables coded on a 5-point Likert 
scale "very inaccurate" through "very accurate" were collapsed and recorded as "inaccurate" versus "accurate" and "strongly disagree" through "strongly agree" as "disagree" versus "agree." Univariate analyses were performed to test the association between sun protection behaviors (low vs high) using the chi-square test for categorical variables and the analysis of variance for continuous variables.

The unadjusted logistic regression was conducted for all variables with $P<.05$ in the univariate analysis followed by the backward, stepwise multivariable regression. Because the number of variables in each family examined (eg, demographics, attitudes toward tanning and sun protection, use of internet, social media, and attitudes toward internet, social media) were relatively few and a single comparison (low vs high sun protection behaviors) was conducted, Bonferroni correction for multiple analyses was not judged to be necessary. All analyses were conducted using IBM SPSS version 25. In addition, $P<.05$ was considered statistically significant. This study was approved by the Institutional Review Board at William Paterson University.

\section{Results}

Table 1 outlines the demographic characteristics, sun protection attitudes and behaviors, and health information-seeking beliefs and attitudes. Of 258 respondents, 63.8\% (164/258) were females. The race was fairly equally distributed with $25.2 \%$ (65/258) black or African American, 28.3\% (73/258) Hispanic, and $31.0 \%(80 / 258)$ white individuals. The mean age of a respondent was 20.3 (SD 4.1) years, and most were freshmen $(156 / 258,60.5 \%)$. Slightly more than half of the respondents declared a health-related major $(135 / 258,52.3 \%)$. No respondents reporting personally having had skin cancer, and few had a friend or family member with skin cancer $(36 / 258$, $14.0 \%)$. Approximately one-third of respondents reported they were "likely" to seek shade $(93 / 258,36.1 \%)$ and use sunscreen on a sunny day $(71 / 258,27.5 \%)$. The majority $(225 / 258,87.2 \%)$ were "very unlikely" or "unlikely" to use a tanning booth and bed, with 92.2\% (238/258) stating they have not used a tanning booth and bed in the past 12 months. Nearly two-thirds were dissatisfied with their appearance at some time in the past, but $57.4 \%$ (148/258) were currently satisfied with their appearance. One-third believed that tanning improved their appearance $(87 / 258,33.7 \%)$, whereas roughly one-quarter believed it improved their self-esteem $(66 / 258,25.6 \%)$ or felt that sun tanning was a way to relieve stress $(60 / 258,23.3 \%)$. The use of social media was limited to about 4.5 hours per day with many $(125 / 258,48.4 \%)$ believing that social media is accurate to some degree and a helpful resource for health information $(108 / 258,41.9 \%)$. 
Table 1. Demographic characteristics, sun protection attitudes and behaviors, and health information-seeking beliefs and attitudes among college students.

\begin{tabular}{|c|c|}
\hline Characteristics & Value $(n=258)$ \\
\hline \multicolumn{2}{|l|}{ Demographics } \\
\hline \multicolumn{2}{|l|}{ Gender, n (\%) } \\
\hline Female & $164(63.8)$ \\
\hline Male & $92(35.7)$ \\
\hline Other & $1(0.4)$ \\
\hline \multicolumn{2}{|l|}{ Race, $n(\%)$} \\
\hline American Indian or Alaskan Native individuals & $1(0.4)$ \\
\hline Asian individuals & $28(10.9)$ \\
\hline Black or African American individuals & $65(25.2)$ \\
\hline Hispanic individuals & $73(28.3)$ \\
\hline Nat Haw or Other Pacific Islander individuals & $1(0.4)$ \\
\hline White individuals & $80(31.0)$ \\
\hline Mixed-race individuals & $3(1.2)$ \\
\hline Other individuals & $7(2.7)$ \\
\hline \multicolumn{2}{|l|}{ Age } \\
\hline Mean (SD) & $20.3(4.1)$ \\
\hline Median & 19.0 \\
\hline Range & $18-59$ \\
\hline \multicolumn{2}{|l|}{ Health-related major, n (\%) } \\
\hline Yes & $135(52.3)$ \\
\hline No & $122(47.3)$ \\
\hline Missing & $1(0.4)$ \\
\hline \multicolumn{2}{|l|}{ College year, n (\%) } \\
\hline Freshmen & $156(60.5)$ \\
\hline Sophomore & $38(14.7)$ \\
\hline Junior & $41(15.9)$ \\
\hline Senior & $20(7.8)$ \\
\hline Graduate student & $0(0.0)$ \\
\hline Other & $3(1.2)$ \\
\hline \multicolumn{2}{|l|}{ Relative with skin cancer, $n(\%)$} \\
\hline Yes & $36(14.0)$ \\
\hline No & $215(83.3)$ \\
\hline Missing & $7(2.7)$ \\
\hline \multicolumn{2}{|l|}{ Self-skin cancer, $\mathbf{n}(\%)$} \\
\hline Yes & $252(97.7)$ \\
\hline No & $0(0.0)$ \\
\hline Missing & $6(2.3)$ \\
\hline \multicolumn{2}{|l|}{ Sun safety and tanning behaviors } \\
\hline \multicolumn{2}{|l|}{ Seek shade on sunny days, $\mathrm{n}(\%)$} \\
\hline Very unlikely & $12(4.7)$ \\
\hline Unlikely & $50(19.4)$ \\
\hline
\end{tabular}




\begin{tabular}{ll}
\hline Characteristics & Value $(\mathrm{n}=25)$ \\
\hline Neutral & $100(38.8)$ \\
Likely & $67(26.0)$ \\
Very likely & $26(10.1)$ \\
Missing & $3(1.2)$ \\
Use sunscreen on a sunny day, $\mathbf{n}(\boldsymbol{\%})$ & $58(22.5)$ \\
Very unlikely & $60(23.3)$ \\
Unlikely & $65(25.2)$ \\
Neutral & $45(17.4)$ \\
Likely & $26(10.1)$ \\
Very likely & $4(1.6)$ \\
Missing &
\end{tabular}

Use of a tanning bed, $n(\%)$

Very unlikely

Unlikely

Neutral

Likely

Very likely

Missing

Number of times tanning booth and bed used in the past $12 \mathrm{mo}, \mathrm{n}(\%)$
$1-2$

$3-5$

$\geq 6$

Missing

Number of lifetime blistering sunburns

Mean (SD)

Median

Range

Reasons for tanning and sun protection, $\mathrm{n}(\%)$

Dissatisfied with appearance

Yes

No

Missing

Currently satisfied with the appearance

Yes

No

Tanning improves appearance

Yes

No

Tanning improves self-esteem

Yes

No
203 (78.7)

22 (8.5)

$20(7.8)$

7 (2.7)

$2(0.8)$

4 (1.6)

238 (92.2)

8 (3.1)

3 (1.2)

8 (3.1)

$1(0.4)$

$1.0(2.3)$

0.0

0-15

$163(63.2)$

$93(36.0)$

$2(0.8)$

148 (57.4)

110 (42.6)

87 (33.7)

$171(66.3)$

66 (25.6)

$191(74.0)$

Sun tanning relieves stress 


\begin{tabular}{|c|c|}
\hline Characteristics & Value $(n=258)$ \\
\hline Yes & $60(23.3)$ \\
\hline No & $193(74.8)$ \\
\hline Missing & $5(1.9)$ \\
\hline \multicolumn{2}{|l|}{ Use of social media } \\
\hline \multicolumn{2}{|c|}{ Social media use (hours per day) } \\
\hline Mean (SD) & $4.5(3.6)$ \\
\hline Median & 4.0 \\
\hline Range & $0-24$ \\
\hline \multicolumn{2}{|l|}{ Social media attitudes, $n(\%)$} \\
\hline \multicolumn{2}{|c|}{ How accurate is social media } \\
\hline Very inaccurate & $38(14.7)$ \\
\hline Inaccurate & $93(36.0)$ \\
\hline Somewhat accurate & $105(40.7)$ \\
\hline Accurate & $15(5.8)$ \\
\hline Very accurate & $5(1.9)$ \\
\hline Missing & $2(0.8)$ \\
\hline \multicolumn{2}{|c|}{ Social media provides helpful health resource } \\
\hline Strongly disagree & $34(13.2)$ \\
\hline Disagree & $74(28.7)$ \\
\hline Somewhat agree & $108(41.9)$ \\
\hline Agree & $34(13.2)$ \\
\hline Strongly agree & $4(1.6)$ \\
\hline Missing & $4(1.6)$ \\
\hline
\end{tabular}

Table 2 presents a comparison of demographic characteristics, sun protection attitudes, and health information-seeking attitudes and behaviors by the level of sun protection behavior. Those who reported "low" sun protection behaviors $(153 / 241,63 \%)$ more often stated that tanning improves one's appearance (43.1\% vs $17.8 \%, P<.001$ ), that tanning improves their self-esteem $(31.4 \%$ vs $15.7 \%, P=.01)$, and that sun tanning relieves stress $(29.1 \%$ vs $12.6 \%, P=.004)$ compared with those with "high" sun protection behaviors. In addition, individuals with "low" sun protection behaviors more often believed that social media was an accurate source of health information (10.5\% vs $3.3 \%, P=.046)$ and a helpful resource for health information $(62.5 \%$ vs $46.7 \%, P=.02)$ compared with those with a "high" sun protection behavior score. More often females (76.7\% vs $57.2 \%, P=.01)$ and those who were in a health-related major $(60.7 \%$ vs $47.7 \%, P=.05)$ had a "high" sun protection behavior score. 
Table 2. The comparison of demographic characteristics, sun protection attitudes, and health information-seeking attitudes and behaviors by the level of sun protection behavior.

\begin{tabular}{|c|c|c|c|c|}
\hline \multirow[t]{2}{*}{ Characteristics } & \multirow[t]{2}{*}{ Total $(\mathrm{n}=258)$} & \multicolumn{2}{|c|}{ Sun protection behaviors $(\mathrm{n}=241)$} & \multirow[t]{2}{*}{$P$ value $^{\mathrm{a}}$} \\
\hline & & Low $(n=153)$ & $\operatorname{High}(\mathrm{n}=90)$ & \\
\hline \multicolumn{5}{|l|}{ Demographics } \\
\hline Gender, n (\%) & & & & .01 \\
\hline Female & $156(64.5)$ & $87(57.2)$ & $69(76.7)$ & \\
\hline Male & $85(35.1)$ & $64(42.1)$ & $21(23.3)$ & \\
\hline Other & $1(0.4)$ & $1(0.7)$ & $0(0.0)$ & \\
\hline Race, $\mathbf{n}(\%)$ & & & & .18 \\
\hline Black or African American individuals & $61(25.1)$ & $34(22.2)$ & $27(30.0)$ & \\
\hline All other races & $182(74.9)$ & $119(77.8)$ & $63(70.0)$ & \\
\hline Age in years, mean (SD) & $20.3(4.1)$ & $20.5(4.7)$ & $19.7(2.7)$ & .17 \\
\hline Health-related major concern, $n(\%)$ & & & & .05 \\
\hline Yes & $127(52.5)$ & $73(47.7)$ & $54(60.7)$ & \\
\hline No & $115(47.5)$ & $80(52.3)$ & $35(39.3)$ & \\
\hline College year, n (\%) & & & & .12 \\
\hline Freshman & $152(62.6)$ & $90(58.8)$ & $62(68.9)$ & \\
\hline Upper classmen & $91(37.4)$ & $63(41.2)$ & $28(31.1)$ & \\
\hline Relative with skin cancer, n (\%) & & & & .54 \\
\hline Yes & $35(14.8)$ & $24(15.9)$ & $11(12.9)$ & \\
\hline No & $201(85.2)$ & $127(84.1)$ & $74(87.1)$ & \\
\hline \multicolumn{5}{|l|}{ Reasons for tanning and sun protection } \\
\hline Dissatisfied with appearance, $n(\%)$ & & & & .68 \\
\hline Yes & $153(63.5)$ & $95(62.5)$ & $58(65.2)$ & \\
\hline No & $88(36.5)$ & $57(37.5)$ & $31(34.8)$ & \\
\hline Currently satisfied with the appearance, $n(\%)$ & & & & .25 \\
\hline Yes & $137(56.4)$ & $82(53.6)$ & $55(61.1)$ & \\
\hline No & $106(43.6)$ & $71(46.4)$ & $35(38.9)$ & \\
\hline Tanning improves appearance, $n(\%)$ & & & & $<.001$ \\
\hline Yes & $82(33.7)$ & $66(43.1)$ & $16(17.8)$ & \\
\hline No & $161(66.3)$ & $87(56.9)$ & $74(82.2)$ & \\
\hline Tanning improves self-esteem, $n(\%)$ & & & & .01 \\
\hline Yes & $62(25.6)$ & $48(31.4)$ & $14(15.7)$ & \\
\hline No & $180(74.4)$ & $105(68.6)$ & $75(84.3)$ & \\
\hline Sun tanning relieves stress, $\mathrm{n}(\%)$ & & & & .004 \\
\hline Yes & $55(23.1)$ & $44(29.1)$ & $11(12.6)$ & \\
\hline No & $183(76.9)$ & $107(70.9)$ & $76(87.4)$ & \\
\hline Use of social media (hours/day), mean (SD) & $4.5(3.6)$ & $4.4(3.2)$ & $5.0(4.4)$ & .22 \\
\hline \multicolumn{5}{|l|}{ Social media attitudes, $\mathrm{n}(\%)$} \\
\hline How accurate is social media & & & & .046 \\
\hline Inaccurate & $224(92.2)$ & $137(89.5)$ & $87(96.7)$ & \\
\hline Accurate & $19(7.8)$ & $16(10.5)$ & $3(3.3)$ & \\
\hline Social media provides helpful health resource & & & & .02 \\
\hline
\end{tabular}




\begin{tabular}{|c|c|c|c|c|}
\hline \multirow[t]{2}{*}{ Characteristics } & \multirow[t]{2}{*}{ Total $(\mathrm{n}=258)$} & \multicolumn{2}{|c|}{ Sun protection behaviors $(\mathrm{n}=241)$} & \multirow[t]{2}{*}{$P$ value ${ }^{\mathrm{a}}$} \\
\hline & & Low $(n=153)$ & High $(n=90)$ & \\
\hline Disagree & $105(43.4)$ & $57(37.5)$ & $48(53.3)$ & \\
\hline Agree & $137(56.6)$ & $95(62.5)$ & $42(46.7)$ & \\
\hline
\end{tabular}

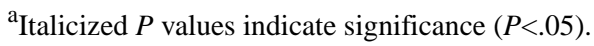

Table 3. Factors associated with high sun protection behaviors.

\begin{tabular}{|c|c|c|c|c|}
\hline \multirow[t]{2}{*}{ Characteristics } & \multicolumn{2}{|l|}{ Unadjusted $\mathrm{OR}^{\mathrm{a}}$} & \multicolumn{2}{|l|}{ Adjusted OR } \\
\hline & $\mathrm{OR}(95 \% \mathrm{CI})$ & $P$ value & $\mathrm{OR}(95 \% \mathrm{CI})$ & $P$ value ${ }^{\mathrm{b}}$ \\
\hline \multicolumn{5}{|l|}{ Gender } \\
\hline Male & 1.00 & Referent & 1.00 & Referent \\
\hline Female & $0.41(0.23-.74)$ & .003 & $0.42(0.22-0.81)$ & .01 \\
\hline \multicolumn{5}{|l|}{ Race } \\
\hline Black or African American individuals & 1.00 & Referent & 1.00 & Referent \\
\hline All other races & $0.67(0.37-1.20)$ & .18 & $0.92(0.47-1.82)$ & .82 \\
\hline \multicolumn{5}{|l|}{ Health-related major concern } \\
\hline No & 1.00 & Referent & 1.00 & Referent \\
\hline Yes & $0.59(0.35-1.00)$ & .052 & $0.63(0.35-1.15)$ & .14 \\
\hline \multicolumn{5}{|l|}{ Suntan improves appearance } \\
\hline No & 1.00 & Referent & 1.00 & Referent \\
\hline Yes & $0.28(0.15-0.53)$ & $<.001$ & $0.25(0.10-0.66)$ & .01 \\
\hline \multicolumn{5}{|l|}{ Suntan improves self-esteem } \\
\hline No & 1.00 & Referent & 1.00 & Referent \\
\hline Yes & $0.41(0.21-0.79)$ & .01 & $1.31(0.41-3.13)$ & .81 \\
\hline \multicolumn{5}{|l|}{ Sun tanning relieves stress } \\
\hline No & 1.00 & Referent & 1.00 & \\
\hline Yes & $0.35(0.17-0.73)$ & .01 & $0.61(0.27-1.38)$ & .24 \\
\hline \multicolumn{5}{|l|}{ Social media is accurate } \\
\hline Disagree & 1.00 & Referent & 1.00 & Referent \\
\hline Agree & $0.30(0.08-1.04)$ & .06 & $0.61(0.15-2.49)$ & .49 \\
\hline \multicolumn{5}{|l|}{ Social media is helpful } \\
\hline Disagree & 1.00 & Referent & 1.00 & Referent \\
\hline Agree & $0.53(0.31-0.89)$ & .02 & $0.60(0.33-1.09)$ & .09 \\
\hline
\end{tabular}

${ }^{\mathrm{a} O R}$ : odds ratio.

${ }^{\mathrm{b}}$ Italicized $P$ values indicate significance $(P<.05)$.

In the unadjusted logistic regression (Table 3), females (odds ratio, OR, 0.41, 95\% CI 0.23-0.74) and individuals who believed a suntan improves appearance (OR 0.28, 95\% CI 0.015-0.53), suntan improves self-esteem (OR 0.41, 95\% CI 0.21-0.79), sun tanning relieves stress (OR $0.35,95 \%$ CI $0.17-0.73$ ), and that social media is a helpful resource for health information were all less likely to have "high" sun protection behaviors. After including all variables in the multivariate model, females (OR $0.42,95 \%$ CI $0.22-0.81$ ) and believers that suntan improves appearance (OR 0.25, 95\% CI 0.10-0.66) remained less likely to have "high" sun protection behaviors.

\section{Discussion}

This study revealed that white female respondents were less likely to have a high sun protection behavior; this is consistent with the literature [16] and remains troubling, as this is a high-risk group for the development of melanoma [3]. In addition, this study corroborates previous research reporting that college students tan for psychosocial reasons, namely appearance $[9,32]$. In addition, this study revealed that those who were dissatisfied with their appearance were markedly 
more likely to believe that suntan improves self-esteem. Interestingly, those who spent more time on the internet were more likely to be dissatisfied with their appearance.

Research indicates that knowledge does not necessarily result in the adoption of healthy behaviors [9]. Reportedly, college students who understand the dangers of tanning and sun exposure, but also feel having a tan is important, often still desire to tan and forego means of sun protection [9,32]. Students in this study reported that they, by and large, felt that information related to health on the internet was accurate. Our ancillary study on HISB delves deeper into how these respondents use the internet to seek health information [31]. A tenet of HISB is that as an individual utilizes technology and understands more about how to use it, the person is more likely to use that specific technology as a source to search and gather health-related information $[33,34]$. Future studies can focus on interventions to ascertain the rate at which college students follow best practices in skin cancer-related HISBs.

Although social media is linked to risky behaviors, this source can incite opportunities for interventions promoting behavioral changes. Key issues can be communicated through popular social media platforms, such as Instagram, Twitter, and Facebook. To effectively address issues related to using Web-based methods, the target population must also understand the purpose of interventions. On the topic of skin cancer, interventions should inform college students regarding the influence of social media on knowledge and attitudes, and how this may lead to the adoption of risky health behaviors. Much like electronic health literacy, media literacy should be carefully utilized to increase the understanding of skin cancer; however, it must be strategic, as audience members may respond differently to an array of communication platforms. For instance, research confirms that young women, in particular, are visually oriented social media users, thus using images with prevention messages may be more effective [18,30]. By improving the methods of Web-based skin cancer prevention, college students may be motivated to appropriately and efficiently engage in HISB and, in turn, adopt healthier behaviors in the long term.

This study has several limitations that warrant mention. First, the cross-sectional design creates the inability to generalize these results. Second, the data were based on self-report and, thus, subject to recall bias. Third, the timing of the survey could influence thoughts and ideas related to sun safety. Despite these limitations, this study contributes to the literature on an important topic.

In sum, sharing content on social media is common. Personal stories of this nature can spark public engagement and result in Web-based search related to skin cancer and prevention [29]. By incorporating personal stories and graphic images with skin cancer prevention messages, this may improve message recall. The degree to which this incites a behavioral change warrants further study. Given that knowledge alone may not necessarily influence behaviors, effective interventions focused on skin cancer prevention and sun protection behaviors must be multifaceted. Furthermore, future research may be able to present critical data on seeking information about health topics (skin cancer, particularly) in social media, an underrecognized area of study.

\section{Conflicts of Interest}

None declared.

\section{References}

1. National Cancer Institute 2018. Skin cancer (including melanoma) URL: https://www.cancer.gov/types/skin [accessed 2018-05-07] [WebCite Cache ID 6zE0jaiDD]

2. Chang C, Murzaku EC, Penn L, Abbasi NR, Davis PD, Berwick M, et al. More skin, more sun, more tan, more melanoma. Am J Public Health 2014 Nov;104(11):e92-e99. [doi: 10.2105/AJPH.2014.302185] [Medline: 25211764]

3. American Cancer Society 2018. Cancer facts and figures 2018 URL: https://www.cancer.org/content/dam/cancer-org/ research/cancer-facts-and-statistics/annual-cancer-facts-and-figures/2018/cancer-facts-and-figures-2018.pdf [accessed 2018-05-07] [WebCite Cache ID 6zE0CDZM8]

4. Whiteman DC, Green AC, Olsen CM. The Growing Burden of Invasive Melanoma: Projections of Incidence Rates and Numbers of New Cases in Six Susceptible Populations through 2031. J Invest Dermatol 2016 Dec;136(6):1161-1171 [FREE Full text] [doi: 10.1016/j.jid.2016.01.035] [Medline: 26902923]

5. Fabbrocini G, Triassi M, Mauriello MC, Torre G, Annunziata MC, De VV, et al. Epidemiology of skin cancer: role of some environmental factors. Cancers (Basel) 2010 Nov 24;2(4):1980-1989 [FREE Full text] [doi: 10.3390/cancers2041980] [Medline: 24281212]

6. Basch CH, Cadorett V, MacLean SA, Hillyer GC, Kernan WD. Attitudes and Behaviors Related to Sun-Safety in College Students. J Community Health 2017 Aug;42(4):757-762. [doi: 10.1007/s10900-017-0314-y] [Medline: 28243774]

7. Glanz K, Jordan A, Lazovich D, Bleakley A. Frequent Indoor Tanners' Beliefs About Indoor Tanning and Cessation. Am J Health Promot 2018 Jan 01:890117118784235. [doi: 10.1177/0890117118784235] [Medline: 29973065]

8. Fabbrocini G, Triassi M, Mauriello MC, Torre G, Annunziata MC, De VV, et al. Epidemiology of skin cancer: role of some environmental factors. Cancers (Basel) 2010 Nov 24;2(4):1980-1989 [FREE Full text] [doi: 10.3390/cancers2041980] [Medline: 24281212]

9. Dennis LK, Lowe JB, Snetselaar LG. Tanning behavior among young frequent tanners is related to attitudes and not lack of knowledge about the dangers. Health Educ J 2009 Sep;68(3):232-243 [FREE Full text] [doi: 10.1177/0017896909345195] [Medline: 22707763] 
10. Zhang M, Qureshi AA, Geller AC, Frazier L, Hunter DJ, Han J. Use of tanning beds and incidence of skin cancer. J Clin Oncol 2012 May 10;30(14):1588-1593 [FREE Full text] [doi: 10.1200/JCO.2011.39.3652] [Medline: 22370316]

11. Duggan M. 2015. Pew Research Center, Int Tech URL: http://www.pewinternet.org/2015/08/19/ mobile-messaging-and-social-media-2015/ [accessed 2018-05-07] [WebCite Cache ID 6zE1DMH1f]

12. Smith A. U.S. Smartphone Use in 2015. 2015. Pew Research Center: Internet \& Technology URL: http://www. pewinternet.org/2015/04/01/us-smartphone-use-in-2015/ [accessed 2018-10-29] [WebCite Cache ID 6zE1TTVb9]

13. Smith A, Anderson M. Social media use in 2018. 2018. Pew Research Center: Internet \& Technology URL: http://www. pewinternet.org/2018/03/01/social-media-use-in-2018/ [accessed 2018-05-07] [WebCite Cache ID 6zE29BciM]

14. Stapleton JL, Hillhouse J, Coups EJ, Pagoto S. Social media use and indoor tanning among a national sample of young adult nonHispanic white women: A cross-sectional study. J Am Acad Dermatol 2016 Jul;75(1):218-220 [FREE Full text] [doi: 10.1016/j.jaad.2016.01.043] [Medline: 27317521]

15. Guy GP, Berkowitz Z, Watson M, Holman DM, Richardson LC. Indoor tanning among young non-Hispanic white females. JAMA Intern Med 2013 Nov 11;173(20):1920-1922 [FREE Full text] [doi: 10.1001/jamainternmed.2013.10013] [Medline: 23959651]

16. Basch CH, Basch CE, Rajan S, Ruggles KV. Use of sunscreen and indoor tanning devices among a nationally representative sample of high school students, 2001-2011. Prev Chronic Dis 2014 Aug 21;11:E144 [FREE Full text] [doi: 10.5888/pcd11.140191] [Medline: 25144679]

17. Boniol M, Autier P, Boyle P, Gandini S. Cutaneous melanoma attributable to sunbed use: systematic review and meta-analysis. BMJ 2012 Jul 24;345:e4757 [FREE Full text] [Medline: 22833605]

18. Mingoia J, Hutchinson AD, Gleaves DH, Corsini N, Wilson C. Use of social networking sites and associations with skin tone dissatisfaction, sun exposure, and sun protection in a sample of Australian adolescents. Psychol Health 2017 Dec;32(12):1502-1517. [doi: 10.1080/08870446.2017.1347788] [Medline: 28691513]

19. McLean SA, Paxton SJ, Wertheim EH, Masters J. Photoshopping the selfie: Self photo editing and photo investment are associated with body dissatisfaction in adolescent girls. Int J Eat Disord 2015 Dec;48(8):1132-1140. [doi: 10.1002/eat.22449] [Medline: 26311205]

20. Meier EP, Gray J. Facebook photo activity associated with body image disturbance in adolescent girls. Cyberpsychol Behav Soc Netw 2014 Apr;17(4):199-206. [doi: 10.1089/cyber.2013.0305] [Medline: 24237288]

21. Myrick JG, Noar SM, Kelley D, Zeitany AE. The Relationships Between Female Adolescents' Media Use, Indoor Tanning Outcome Expectations, and Behavioral Intentions. Health Educ Behav 2017 Dec;44(3):403-410. [doi:

10.1177/1090198116667251] [Medline: 27590838]

22. Banerjee SC, Rodríguez VM, Greene K, Hay JL. Trending on Pinterest: an examination of pins about skin tanning. Transl Behav Med 2018 Apr 10. [doi: 10.1093/tbm/iby036] [Medline: 29648613]

23. Basch CH, Hillyer GC, Basch CE. Descriptive analysis of articles and advertisements pertaining to skin cancer prevention in 2 popular US parenting magazines, 2000-2010. Prev Chronic Dis 2013 Apr 04;10:E48 [FREE Full text] [doi: 10.5888/pcd10.120200] [Medline: 23557639]

24. Basch CH, Mongiovi J, Hillyer GC, Fullwood MD, Ethan D, Hammond R. An Advertisement and Article Analysis of Skin Products and Topics in Popular Women's Magazines: Implications for Skin Cancer Prevention. Health Promot Perspect 2015 Jan;5(4):261-268 [FREE Full text] [doi: 10.15171/hpp.2015.031] [Medline: 26933645]

25. Basch CH, Ethan D, Hillyer GC, Berdnik A. Skin cancer prevention coverage in popular US women's health and fitness magazines: an analysis of advertisements and articles. Glob J Health Sci 2014 Apr 02;6(4):42-48 [FREE Full text] [doi: 10.5539/gjhs.v6n4p42] [Medline: 24999136]

26. Basch CH, Hillyer GC, Ethan D, Berdnik A, Basch CE. Tanning Shade Gradations of Models in Mainstream Fitness and Muscle Enthusiast Magazines: Implications for Skin Cancer Prevention in Men. Am J Mens Health 2015 Jul;9(4):301-306. [doi: 10.1177/1557988314543511] [Medline: 25038234]

27. Cho H, Lee S, Wilson K. Magazine exposure, tanned women stereotypes, and tanning attitudes. Body Image 2010 Sep;7(4):364-367 [FREE Full text] [doi: 10.1016/j.bodyim.2010.04.002] [Medline: 20573553]

28. Ricklefs CA, Asdigian NL, Kalra HL, Mayer JA, Dellavalle RP, Holman DM, et al. Indoor tanning promotions on social media in six US cities \#UVTanning \#tanning. Transl Behav Med 2016 Dec;6(2):260-270 [FREE Full text] [doi: 10.1007/s13142-015-0378-0] [Medline: 27356996]

29. Noar SM, Leas E, Althouse BM, Dredze M, Kelley D, Ayers JW. Can a selfie promote public engagement with skin cancer? Prev Med 2018 Jun;111:280-283. [doi: 10.1016/j.ypmed.2017.10.038] [Medline: 29109014]

30. Falzone AE, Brindis CD, Chren M, Junn A, Pagoto S, Wehner M, et al. Teens, Tweets, and Tanning Beds: Rethinking the Use of Social Media for Skin Cancer Prevention. Am J Prev Med 2017 Sep;53(3S1):S86-S94 [FREE Full text] [doi: 10.1016/j.amepre.2017.04.027] [Medline: 28818251]

31. MacLean SA, Basch CH, Clark A, Basch CE. Readability of information on colonoscopy preparation on the internet. Health Promot Perspect 2018 Apr;8(2):167-170 [FREE Full text] [doi: 10.15171/hpp.2018.22] [Medline: 29744314]

32. Harrington CR, Beswick TC, Leitenberger J, Minhajuddin A, Jacobe HT, Adinoff B. Addictive-like behaviours to ultraviolet light among frequent indoor tanners. Clin Exp Dermatol 2011 Jan;36(1):33-38. [doi: 10.1111/j.1365-2230.2010.03882.x] [Medline: 20545951] 
33. Britt RK, Collins WB, Wilson K, Linnemeier G, Englebert AM. eHealth Literacy and Health Behaviors Affecting Modern College Students: A Pilot Study of Issues Identified by the American College Health Association. J Med Internet Res 2017 Dec 19;19(12):e392 [FREE Full text] [doi: 10.2196/jmir.3100] [Medline: 29258979]

34. Norman CD, Skinner HA. eHEALS: The eHealth Literacy Scale. J Med Internet Res 2006 Nov;8(4):e27 [FREE Full text] [doi: 10.2196/jmir.8.4.e27] [Medline: $\underline{\text { 17213046] }}$

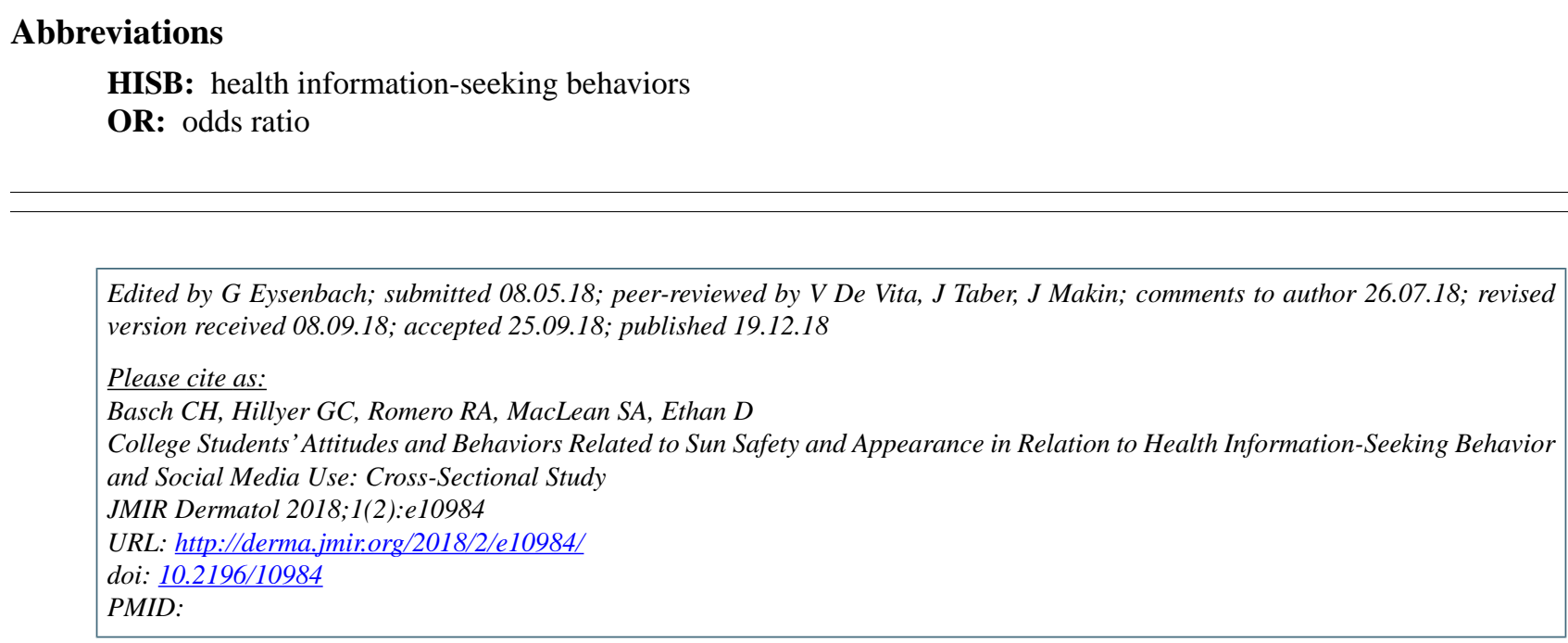

(C) Corey H Basch, Grace C Hillyer, Rachelle-Ann Romero, Sarah A MacLean, Danna Ethan. Originally published in JMIR Dermatology (http://derma.jmir.org), 19.12.2018. This is an open-access article distributed under the terms of the Creative Commons Attribution License (https://creativecommons.org/licenses/by/4.0/), which permits unrestricted use, distribution, and reproduction in any medium, provided the original work, first published in JMIR Dermatology Research, is properly cited. The complete bibliographic information, a link to the original publication on http://derma.jmir.org, as well as this copyright and license information must be included. 